\title{
BMJ open Impact of walking on life expectancy and lifetime medical expenditure: the Ohsaki Cohort Study
}

\author{
Masato Nagai, ${ }^{1}$ Shinichi Kuriyama, ${ }^{1,2}$ Masako Kakizaki, ${ }^{1}$ Kaori Ohmori-Matsuda, ${ }^{1}$ \\ Toshimasa Sone, ${ }^{1}$ Atsushi Hozawa, ${ }^{1,4}$ Miyuki Kawado, ${ }^{5}$ Shuji Hashimoto, ${ }^{5}$ \\ Ichiro Tsuji ${ }^{1}$
}

To cite: Nagai M, Kuriyama S, Kakizaki M, et al. Impact of walking on life expectancy and lifetime medical expenditure: the Ohsaki Cohort Study. BMJ Open 2011;1:e000240. doi:10. 1136/bmjopen-2011000240

- Prepublication history for this paper is available online. To view these files please visit the journal online (http:// bmjopen.bmj.com).

Received 28 June 2011 Accepted 25 August 2011

This final article is available for use under the terms of the Creative Commons Attribution Non-Commercial 2.0 Licence; see http://bmjopen.bmj.com

For numbered affiliations see end of article.

Correspondence to Dr Masato Nagai; m-nagai@med.tohoku.ac.jp

\section{ABSTRACT}

Objective: People who spend a longer time walking have lower demands for medical care. However, in view of their longer life expectancy, it is unclear whether their lifetime medical expenditure increases or decreases. The present study examined the association between time spent walking, life expectancy and lifetime medical expenditure.

Method: The authors followed up 27738 participants aged $40-79$ years and prospectively collected data on their medical expenditure and survival covering a 13-year-period. Participants were classified into those walking $<1$ and $\geq 1 \mathrm{~h}$ per day. The authors constructed life tables and estimated the life expectancy and lifetime medical expenditure from 40 years of age using estimate of multiadjusted mortality and medical expenditure using a Poisson regression model and linear regression model, respectively.

Results: Participants who walked $\geq 1 \mathrm{~h}$ per day have a longer life expectancy from 40 years of age than participants who walked $<1 \mathrm{~h}$ per day. The multiadjusted life expectancy for those who walked $\geq 1 \mathrm{~h}$ per day was 44.81 years, significantly lower by 1.38 years in men $(p=0.0073)$ in men and 57.78 years in women, non-significantly lower by 1.16 years in women $(p=0.2351)$. In addition to their longer life expectancy, participants who walked $\geq 1 \mathrm{~h}$ per day required a lower lifetime medical expenditure from 40 years of age than participants who walked $<1 \mathrm{~h}$ per day. The multiadjusted lifetime medical expenditure for those who walked $\geq 1 \mathrm{~h}$ per day was $£ 99423.6$, significantly lower by $7.6 \%$ in men $(p=0.0048)$ and $£ 128161.2$, non-significantly lower by $2.7 \%$ in women $(p=0.2559)$.

Discussion: Increased longevity resulting from a healthier lifestyle does not necessarily translate into an increased amount of medical expenditure throughout life. Encouraging people to walk may extend life expectancy and decrease lifetime medical expenditure, especially for men.

\section{INTRODUCTION}

Previous studies have agreed that a higher level of physical activity extends life expect-

\section{ARTICLE SUMMARY}

\section{Article focus}

- Medical expenditure per month was reduced when the amount of time spent walking was increased.

- Walking is associated with a decreased risk of mortality.

- In view of the increased life expectancy of those who walk longer, it is unclear whether lifetime medical expenditure increases or decreases as a result.

\section{Key messages}

- Lifetime medical expenditure from the age of 40 years for men and women who walked $\geq 1 \mathrm{~h}$ per day was reduced by $7.6 \%$ and $2.7 \%$, respectively, in comparison with those who walked $<1 \mathrm{~h}$ per day.

- Years of life added as a result of a healthy lifestyle did not necessarily translate into an increased amount of lifetime medical expenditure.

Strengths and limitations of this study

n This is the first study to investigate the association between walking, life expectancy and lifetime medical expenditure.

- We assessed walking using a simple questionnaire, in which we asked the participants to report only the time spent walking, and did not ask about walking pace, distance walked or any distinction between walking for exercise and other reasons.

ancy. ${ }^{1-4}$ Walking is part of a physically active lifestyle. Previous studies have indicated that a longer time spent walking, ${ }^{5-13}$ walking pace $^{814-16}$ and a longer distance walked ${ }^{17} 18$ are significantly associated with a decreased risk of mortality.

We previously reported that medical expenditure per month was significantly reduced among those who spent a longer time walking, based on the same cohort dataset as that used here. ${ }^{19}$ Similar findings have been reported worldwide. ${ }^{20}{ }^{21}$ However, 
in view of the increased life expectancy of those who walk for a longer time, it is unclear whether lifetime medical expenditure increases or decreases as a result. In other words, the question to be answered here is whether a lifelong healthy lifestyle eventually increases lifetime medical expenditure because of extended life expectancy.

So far, only one study has examined the association between physical activity and lifetime costs. ${ }^{4}$ This revealed that people with a high physical activity level tended to live longer than people with a lower physical activity level, and that the former had lower lifetime medical costs than the latter. However, that study was only a simulation analysis based on assumed variations in the health and economic effects of active and sedentary lifestyles.

The objective of the present study was to examine the association between walking, life expectancy and lifetime medical expenditure using actual individual data derived from a population-based 13-year prospective observation period. The population comprised 27738 Japanese adults aged 40-79 years living in the community who were free of any functional limitations or chronic conditions interfering with physical activity, with an accrued total of 285342 person-years. This cohort study has been monitoring survival and medical care utilisation, and its costs, for all participants. ${ }^{19}{ }^{22}$ Using this dataset, we constructed a life table to estimate life expectancy and lifetime medical expenditure according to the time spent walking. ${ }^{24} 25$

\section{MATERIALS AND METHODS \\ Study cohort}

The present data were derived from the Ohsaki National Health Insurance (NHI) Cohort Study. ${ }^{19} \quad 22 \quad 25$ We conducted a self-administered questionnaire survey of various lifestyle habits between October and December 1994 for all NHI beneficiaries aged 40-79 years who lived in the catchment area of Ohsaki Public Health Center, Miyagi Prefecture, northeastern Japan. Out of 54996 eligible individuals, $52029(95 \%)$ responded.

We excluded 776 participants who had withdrawn from the NHI before 1 January 1995 because their cost data were not available. Thus, the remaining 51253 participants formed the study cohort. The study protocol was approved by the Ethics Committee of Tohoku University School of Medicine. Participants who had returned the self-administered questionnaires and signed them were considered to have consented to participate.

For the present analysis, we excluded participants who had functional limitation or chronic conditions interfering with physical activity. Physical function status was assessed using the six-item measure of the Medical Outcomes Study Short-form General Health Survey. ${ }^{26}$ Participants were excluded if they stated on the Medical Outcomes Study questionnaire that they were unable to perform moderate or vigorous activities $(n=15916)$. We excluded participants who reported severe bodily pain $(\mathrm{n}=949)$, or any history of stroke $(\mathrm{n}=474)$, myocardial infarction $(n=585)$ or arthritis $(n=2176)$. We also excluded those who died within the first year $(n=174)$ or did not provide complete responses in the walking status questionnaire $(\mathrm{n}=3241)$. Thus, a total of 27738 participants (15521 men and 12217 women) remained. These participants were apparently healthy enough to walk for as long as they wished.

\section{Time spent walking}

The self-administered questionnaire included items on time spent walking. Time spent walking was assessed through the subject's response to the question, 'About how much time do you walk per day on average?' The participants were asked to choose one of three answers: ' 1 h or more,' ' 30 min -1 h' or ' 30 min or less.' In Japan, the Ministry of Health, Labour and Welfare recommended to walk $\geq 1 \mathrm{~h}$ per day in Exercise and Physical Activity Reference for Health Promotion 2006. Then, we divided the participants into two groups according to the time spent walking daily: $<1 \mathrm{~h}$ and $\geq 1 \mathrm{~h}$. We had previously evaluated and reported the validity of self-reported time spent walking. ${ }^{5} 1927$ This validation study had indicated that self-reported walking time was reasonably reproducible and sufficiently valid for studying the health effects of walking.

\section{Health-insurance system in Japan}

Details of the Japanese NHI system have been described previously. ${ }^{22} 28{ }^{29}$ Briefly, everyone living in Japan is required to enrol in a health-insurance system. The NHI covers $35 \%$ of the Japanese population, mainly farmers, self employed or retired people. The NHI covers almost all medical treatment, including diagnostic tests, medication, surgery, supplies and materials, physicians and other personnel costs, inpatient care and most dental treatment. It covers treatment by physicians and nurses but not that by other professionals such as home health aides. Payment to medical providers is made on a feefor-service basis, where the price of each service is determined by a uniform national fee schedule.

When a participant withdraws from the NHI system because of death, emigration or employment, the withdrawal date and its reason are coded in the NHI withdrawal history files. We recorded any mortality or migration by reviewing the NHI withdrawal history files and collected data on the death of participants by reviewing the death certificates filed at Ohsaki Public Health Center. We thus followed up the participants and prospectively collected data on medical care utilisation and its costs for all individuals in the cohort from 1 January 1995 to 31 December 2007. Study participants $(16.3 \%)$ were lost to follow-up, so their vital status was unknown.

\section{Statistical analysis}

Using the Ohsaki NHI cohort database, we estimated mortality and medical expenditure for individual age 
groups, and for the categories of time spent walking, for both men and women. We divided age into the following groups: $40-44,45-49,50-54,55-59,60-64,65-69$, $70-74,75-79,80-84$ and $\geq 85$ years. The multiadjusted mortalities for each age category were estimated from a Poisson regression model based on person-years and the number of deaths from 1996 until 2007. The dependent variable was mortality, and the independent variables were age groups, categories of time spent walking and the following covariates: smoking status (current and past smoker, or never smoker), alcohol consumption (current drinker consuming 1-499 g/ week, current drinker consuming $\geq 450 \mathrm{~g}$ /week, or never and past drinker), body mass index (BMI: $<21 \mathrm{~kg} / \mathrm{m}^{2}, 21-24.9 \mathrm{~kg} / \mathrm{m}^{2}$ or $\geq 25 \mathrm{~kg} / \mathrm{m}^{2}$ ), self-rated health (good or not good), sports and physical activity ( $\geq 3 \mathrm{~h} /$ week or $<3 \mathrm{~h} /$ week), history of hypertension disease (presence or absence), history of diabetes mellitus (presence or absence), history of cancer (presence or absence), history of liver disease (presence or absence) and history of kidney disease (presence or absence).$^{19}$ The data on all covariates were obtained from a self-administered questionnaire. We estimated the mortality of participants aged $\geq 85$ years by multiplying the estimated mortality for the $85-89$ year age group by the ratio of mortality for the same age group relative to the mortality for $\geq 85$ years from complete life tables for the year 2000, as there were few person-years for participants aged over 90 years in our dataset. $^{30}$

Because medical expenditure increases before death, we separately calculated medical expenditure for participants who survived through the index year and for those who died. The multiadjusted medical expenditure per year for survivors and decedents, respectively, was estimated for each of the age groups and the categories of time spent walking using a linear regression model adjusted for the above covariates.

The estimates of multiadjusted mortality and medical expenditure for each age group were used for estimating life expectancy and lifetime medical expenditure from 40 years of age. Life expectancy was calculated using Chiang's analytical method on the basis of the latest published complete life tables of Japan for the year 2000. ${ }^{23} 30$ Lifetime medical expenditure was estimated from the sum obtained by multiplying the static population in life table by the medical expenditure for survivors and the number of deaths in the life table by the increased medical expenditure owing to death, which was calculated by subtracting the medical expenditure in year of survivors from that in the period of 1 year before death. That is, the life expectancy $\left(\mathrm{e}_{\mathrm{x}}\right)$ and lifetime medical expenditure $\left(\mathrm{M}_{\mathrm{e}}\right)$ for each age group $(\mathrm{x})$ were estimated using the numbers of survivors $\left(l_{\mathrm{x}}\right)$, deaths $\left(\mathrm{d}_{\mathrm{x}}\right)$, static population $\left(\mathrm{L}_{\mathrm{x}}\right)$, multiadjusted medical expenditure for survivors $\left(a_{y}\right)$ and multiadjusted medical expenditure for the deceased $\left(b_{y}\right)$ as follows: $\sum$ is the sum of $y \geq x$

$$
\begin{gathered}
\mathrm{e}_{\mathrm{x}}=\frac{\sum \mathrm{L}_{\mathrm{y}}}{\mathrm{l}_{\mathrm{x}}} \\
\mathrm{M}_{\mathrm{x}}=\frac{\sum\left(\mathrm{L}_{\mathrm{y}} \mathrm{a}_{\mathrm{y}}+\mathrm{d}_{\mathrm{y}} \mathrm{b}_{\mathrm{y}}\right)}{\mathrm{l}_{\mathrm{x}}}
\end{gathered}
$$

The $95 \%$ CIs were estimated using a Monte Carlo simulation with 100000 replicates based on a Poisson regression model and linear regression model. All analyses were used the SAS V.9.1 statistical software package.

We used a purchasing-power parity rate (British pounds to Japanese yen) of $£ 1.00=¥ 140$.

\section{RESULTS}

After 13 years of follow-up, we observed 2936 deaths (2193 men and 743 women) among the 27738 participants (15521 men and 12217 women). The mean medical expenditure per year for survivors who walked $\geq 1 \mathrm{~h}$ per day was $£ 1714.2$ in men and $£ 1621.4$ in women, significantly lower than for those who walked $<1 \mathrm{~h}$ per day (men: £2064.3, p<0.0001; women: £1878.6, $\mathrm{p}<0.0001)$. Also, the mean medical expenditure in the year of death for participants who walked $\geq 1 \mathrm{~h}$ per day was $£ 16878.6$ in men and $£ 17464.3$ in women, which was not significantly different from those who walked $<1 \mathrm{~h}$ per day (men: $£ 16650.0, p=0.7315$; women: $£ 17742.9$, $\mathrm{p}=0.8330)$.

\section{Baseline characteristics in terms of categories for time spent walking}

Table 1 shows the baseline characteristics of the study participants according to the categories of time spent walking for men and women, respectively.

As compared with those who walked $<1 \mathrm{~h}$ per day, participants who walked $\geq 1 \mathrm{~h}$ per day were less likely to be smokers and obese. Self-reported histories of hypertension, diabetes mellitus and liver disease were all significantly less prevalent in those who walked $\geq 1 \mathrm{~h}$ per day.

\section{Mortality in terms of categories for time spent walking}

Figure 1A (for men) and Figure 1B (for women) show the multiadjusted mortality (per 1000) in each of the age groups according to the categories of time spent walking.

In men in each age group, the multiadjusted mortality was lower in participants who walked $\geq 1 \mathrm{~h}$ per day than in those who walked $<1 \mathrm{~h}$ per day. In women in all age groups except for the aged 40-44 and 45-49 year groups, the multiadjusted mortality was lower in participants who walked $\geq 1 \mathrm{~h}$ per day than in those who walked $<1 \mathrm{~h}$ per day. 
Table 1 Baseline characteristics by time-spent-walking categories in 27738 participants

\begin{tabular}{|c|c|c|c|c|c|c|}
\hline & \multicolumn{3}{|l|}{ Men } & \multicolumn{3}{|l|}{ Women } \\
\hline & \multicolumn{3}{|c|}{ Time spent walking } & \multicolumn{3}{|c|}{ Time spent walking } \\
\hline & $<1 \mathrm{~h}$ & $\geq 1 \mathrm{~h}$ & p Value* & $<1 \mathrm{~h}$ & $\geq 1 \mathrm{~h}$ & p Value* \\
\hline No of subjects & 7363 & 8158 & 0.2784 & 6303 & 5914 & 0.0714 \\
\hline Mean (SD) age & $57.4(10.6)$ & $57.2(10.2)$ & & $57.9(10.1)$ & $57.6(9.7)$ & \\
\hline \multicolumn{7}{|l|}{ Smoking status (\%) } \\
\hline Current and past smoker & 81.9 & 79.8 & 0.0011 & 12.6 & 9.9 & $<0.0001$ \\
\hline Never smoker & 18.1 & 20.2 & & 87.5 & 90.1 & \\
\hline \multicolumn{7}{|l|}{ Alcohol drinking (\%) } \\
\hline Never and past drinker & 26.5 & 25.1 & 0.1117 & 74.7 & 75.4 & 0.1380 \\
\hline $\begin{array}{l}\text { Current drinker, } \\
1-449 \mathrm{~g} / \text { week }\end{array}$ & 61.3 & 62.2 & & 24.3 & 23.9 & \\
\hline $\begin{array}{l}\text { Current drinker, } \\
\geq 450 \mathrm{~g} / \text { week }\end{array}$ & 12.2 & 12.8 & & 1.1 & 0.7 & \\
\hline \multicolumn{7}{|l|}{ Body mass index (\%) } \\
\hline$<21 \mathrm{~kg} / \mathrm{m}^{2}$ & 18.5 & 20.5 & $<0.0001$ & 18.6 & 19.4 & 0.0019 \\
\hline $21-24.9 \mathrm{~kg} / \mathrm{m}^{2}$ & 53.3 & 55.8 & & 50.7 & 52.9 & \\
\hline$\geq 25 \mathrm{~kg} / \mathrm{m}^{2}$ & 28.3 & 23.7 & & 30.7 & 27.7 & \\
\hline \multicolumn{7}{|l|}{ Self-rated health (\%) } \\
\hline Good & 73.1 & 79.3 & $<0.0001$ & 72.5 & 78.2 & $<0.0001$ \\
\hline Not good & 26.9 & 20.7 & & 27.5 & 21.8 & \\
\hline \multicolumn{7}{|c|}{ Sports and physical activity (\%) } \\
\hline$\geq 3 \mathrm{~h} /$ week & 13.2 & 18.7 & $<0.0001$ & 10.7 & 16.6 & $<0.0001$ \\
\hline$<3 \mathrm{~h} /$ week & 86.8 & 81.3 & & 89.3 & 83.4 & \\
\hline \multicolumn{7}{|l|}{ History of hypertension (\%) } \\
\hline Presence & 21.5 & 18.6 & $<0.0001$ & 24.2 & 20.1 & $<0.0001$ \\
\hline Absence & 78.5 & 81.4 & & 75.8 & 79.9 & \\
\hline \multicolumn{7}{|c|}{ History of diabetes mellitus (\%) } \\
\hline Presence & 7.4 & 4.8 & $<0.0001$ & 5.1 & 3.2 & $<0.0001$ \\
\hline Absence & 92.6 & 95.2 & & 94.9 & 96.8 & \\
\hline \multicolumn{7}{|l|}{ History of cancer (\%) } \\
\hline Presence & 2.1 & 1.8 & 0.2563 & 2.8 & 2.8 & 0.9032 \\
\hline Absence & 97.9 & 98.2 & & 97.2 & 97.2 & \\
\hline \multicolumn{7}{|l|}{ History of liver disease (\%) } \\
\hline Presence & 6.9 & 5.7 & 0.0013 & 3.7 & 2.9 & 0.0223 \\
\hline Absence & 93.1 & 94.4 & & 96.3 & 97.1 & \\
\hline \multicolumn{7}{|l|}{ History of kidney disease (\%) } \\
\hline Presence & 2.9 & 2.7 & 0.3493 & 3.6 & 2.7 & 0.0049 \\
\hline Absence & 97.1 & 97.3 & & 96.4 & 97.3 & \\
\hline
\end{tabular}

Table 2 shows the mortality ratio with $95 \%$ CIs according to the categories of time spent walking. In men, the multiadjusted mortality ratio for participants who walked $\geq 1 \mathrm{~h}$ per day was significantly lower than that for participants who walked $<1 \mathrm{~h}$ per day $(0.90,95 \%$ CI 0.82 to $0.98, \mathrm{p}=0.0153)$. In women, the multiadjusted mortality ratio for participants who walked $\geq 1 \mathrm{~h}$ per day was nonsignificantly lower than that for participants who walked $<1 \mathrm{~h}$ per day $(0.95,95 \%$ CI 0.82 to $1.10, \mathrm{p}=0.4693)$.

\section{Life expectancy and lifetime medical expenditure in terms} of time spent walking

Table 3 shows the life expectancy and lifetime medical expenditure from 40 years of age with $95 \%$ CIs according to the categories of time spent walking.

In men, the multiadjusted life expectancy of those who walked $\geq 1 \mathrm{~h}$ per day was 44.81 years $(95 \%$ CI 43.66 to
45.94), which was significantly longer by 1.38 years $(\mathrm{p}=0.0073)$ than for those who walked $<1 \mathrm{~h}$ per day (43.43 years; $95 \%$ CI 42.39 to 44.41 ). In women, the same results were observed, although the differences did not reach statistical significance.

In spite of their longer life expectancy, their lifetime medical expenditure from 40 years of age was significantly lower in men and non-significantly lower in women. The multiadjusted lifetime medical expenditure for participants who walked $\geq 1 \mathrm{~h}$ per day was $£ 99423.6$ (95\% CI 92515.9 to 106694.7$)$, significantly lower by $7.6 \%(p=0.0048)$ than for those who walked $<1 \mathrm{~h}$ per day (£107544.2; 95\% CI 101234.0 to 114044.6). In women, the multiadjusted lifetime medical expenditure for participants who walked $\geq 1 \mathrm{~h}$ per day was £128161.2 (95\% CI 111335.0 to 148494.7 ), non-significantly lower by $2.7 \% \quad(p=0.2559)$ than for 

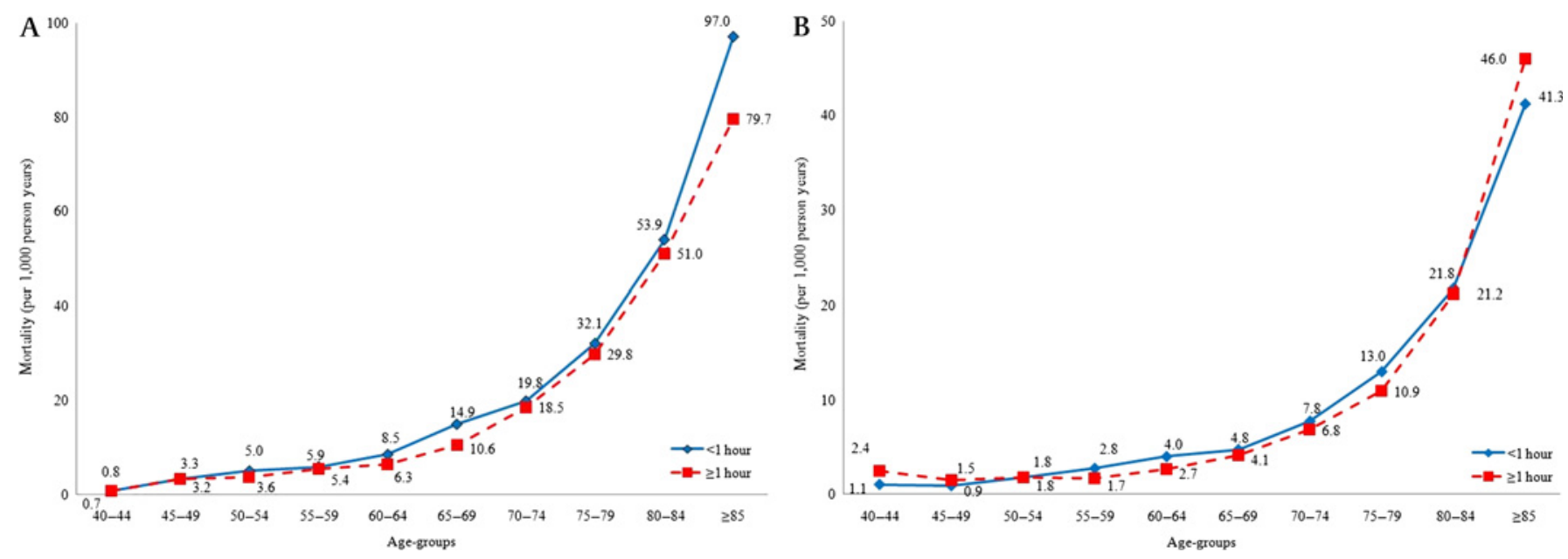

Figure 1 Multiadjusted mortality by time-spent-walking categories in each age group in $(A)$ men and $(B)$ women.

those who walked $<1 \mathrm{~h}$ per day $(£ 131766.8 ; 95 \%$ CI 115902.4 to 150714.3$)$.

\section{DISCUSSION}

The present results indicate that the multiadjusted lifetime medical expenditure from the age of 40 years for those who walked $\geq 1 \mathrm{~h}$ per day was significantly lower by $7.6 \%$ in men and non-significantly lower by $2.7 \%$ in women than for those who walked $<1 \mathrm{~h}$ per day. This decrease in lifetime medical expenditure was observed in spite of a longer life expectancy ( 1.38 years for men and 1.16 years for women) among those who walked $\geq 1 \mathrm{~h}$ per day. Thus, a healthy lifestyle not only extended longevity but also decreased the amount of lifetime medical expenditure, especially men.

We observed statistically significant differences for men but not for women. Although the differences did not reach statistical significance, the same results were observed for women. The reason why the impact of walking was smaller in women than in men was unknown. In women, other factors such as obesity and postmenopausal change might have a stronger impact on life expectancy and lifetime medical expenditure than walking.

\section{Comparison with other studies}

Four studies have addressed the association between physical activity level and life expectancy. ${ }^{1-4}$ Additionally, studies investigating associations between time spent walking, ${ }^{5-13}$ or distance walked ${ }^{17} 18$ and mortality have consistently shown that participants who have a higher physical activity have a longer life expectancy and lower mortality than participants who have a lower physical activity. Only one study has reported the association between physical activity and lifetime medical expenditure. ${ }^{4}$ In a simulation study, Keeler et al demonstrated that if participants with a sedentary lifestyle had exercised regularly, the additional exercise would have increased their life expectancy by 300 days and saved $£ 1900$ in lifetime costs. Even though there is a difference between physical activity and walking, this result is consistent with the present finding that participants who walked $\geq 1 \mathrm{~h}$ per day lived longer and had a lower lifetime medical expenditure.

We previously calculated life expectancy and lifetime medical expenditure in relation to smoking and BMI from age 40 years using the same dataset as that for the present study. ${ }^{24}$ The results indicated that lifetime medical expenditure was lower for smokers than for non-smokers, reflecting the 3.5-year shorter life expectancy of smokers. ${ }^{24}$ On the other hand, lifetime medical expenditure was higher for participants who were obese $(\mathrm{BMI} \geq 30.0)$ than for those who were of normal weight $(18.5 \leq \mathrm{BMI}<25.0)$, even though the former lived 2 years less than the latter (Nagai M, Kuriyama S, Kakizaki M, et al. Impact of obesity, overweight and underweight on life expectancy and lifetime medical expenditures. Popul Health Metr, under review). In fact, both smokers and obese participants had a shorter life expectancy than non-smokers and normal-weight participants, whereas their lifetime medical expenditure was conversely

Table 2 Mortality ratio for time-spent-walking categories in 27738 participants

\begin{tabular}{|c|c|c|c|c|c|}
\hline & & \multicolumn{2}{|l|}{ Univariate } & \multicolumn{2}{|l|}{ Multiadjusted* } \\
\hline \multicolumn{2}{|c|}{ Time spent walking } & Mortality ratio $(95 \% \mathrm{Cl})$ & p Value & Mortality ratio $(95 \% \mathrm{Cl})$ & p Value \\
\hline \multirow[t]{2}{*}{ Men } & $<1 \mathrm{~h}$ & 1.00 & & 1.00 & \\
\hline & $\geq 1 \mathrm{~h}$ & 0.87 (0.80 to 0.94$)$ & 0.0009 & 0.90 (0.82 to 0.98$)$ & 0.0153 \\
\hline \multirow[t]{2}{*}{ Women } & $<1 \mathrm{~h}$ & 1.00 & & 1.00 & \\
\hline & $\geq 1 \mathrm{~h}$ & 0.89 (0.77 to 1.03$)$ & 0.1135 & $0.95(0.82$ to 1.10$)$ & 0.4693 \\
\hline
\end{tabular}

*Adjusted for age groups, smoking status, alcohol drinking, body mass index, self-rated health, sports and physical activity, and history of hypertension, diabetes mellitus, cancer, liver disease and kidney disease. 
Table 3 Life expectancy and lifetime medical expenditure at age 40 years for time-spent-walking categories in 27738 participants

\begin{tabular}{|c|c|c|c|c|c|c|c|}
\hline & \multirow{2}{*}{$\begin{array}{l}\text { Time } \\
\text { spent walking }\end{array}$} & \multicolumn{3}{|l|}{ Univariate } & \multicolumn{3}{|c|}{ Multiadjusted* } \\
\hline & & Estimate & $95 \% \mathrm{Cl}$ & p Value & Estimate & $95 \% \mathrm{Cl}$ & p Value \\
\hline \multirow[t]{6}{*}{ Men } & \multicolumn{7}{|c|}{ Life expectancy (years) at age 40 years } \\
\hline & $<1 \mathrm{~h}$ & 42.41 & 41.45 to 43.26 & \multirow[t]{2}{*}{0.0004} & 43.43 & 42.39 to 44.41 & \multirow[t]{2}{*}{0.0073} \\
\hline & $\geq 1 \mathrm{~h}$ & 44.19 & 43.15 to 45.19 & & 44.81 & 43.66 to 45.94 & \\
\hline & \multicolumn{7}{|c|}{ Lifetime medical expenditure $(£)$ at age 40 years } \\
\hline & $<1 \mathrm{~h}$ & 107023.2 & $\begin{array}{l}101093.6 \text { to } \\
113066.3\end{array}$ & \multirow[t]{2}{*}{$<0.0001$} & 107544.2 & $\begin{array}{l}101234.0 \text { to } \\
114044.6\end{array}$ & \multirow[t]{2}{*}{0.0048} \\
\hline & $\geq 1 \mathrm{~h}$ & 94402.1 & $\begin{array}{l}87812.3 \text { to } \\
101248.0\end{array}$ & & 99423.6 & $\begin{array}{l}92515.9 \text { to } \\
106694.7\end{array}$ & \\
\hline \multirow[t]{6}{*}{ Women } & \multicolumn{7}{|c|}{ Life expectancy (years) at age 40 years } \\
\hline & $<1 \mathrm{~h}$ & 52.25 & 49.79 to 54.92 & \multirow[t]{2}{*}{0.0569} & 56.62 & 53.17 to 60.62 & \multirow[t]{2}{*}{0.2351} \\
\hline & $\geq 1 \mathrm{~h}$ & 54.25 & 51.38 to 57.48 & & 57.78 & 54.02 to 62.22 & \\
\hline & \multicolumn{7}{|c|}{ Lifetime medical expenditure $(£)$ at age 40 years } \\
\hline & $<1 \mathrm{~h}$ & 123553.0 & $\begin{array}{l}111619.5 \text { to } \\
137549.6\end{array}$ & 0.0644 & 131766.8 & $\begin{array}{l}115902.4 \text { to } \\
150714.3\end{array}$ & \multirow[t]{2}{*}{0.2559} \\
\hline & $\geq 1 \mathrm{~h}$ & 115896.0 & $\begin{array}{l}102406.6 \text { to } \\
131792.1\end{array}$ & & 128161.2 & $\begin{array}{l}111335.0 \text { to } \\
148494.7\end{array}$ & \\
\hline
\end{tabular}

*Adjusted for age groups, smoking status, alcohol drinking, body mass index, self-rated health, sports and physical activity, and history of hypertension, diabetes mellitus, cancer, liver disease and kidney disease as same as table 2.

increased. These differences could be explained by the impact of these risk factors on quality of life. Using prospective data for 16176 adult Caucasians in the USA, ${ }^{31}$ Reuser et al estimated life expectancy and years of life with and without activities of daily-living disability in relation to smoking and $\mathrm{BMI}$, respectively. The results indicated that smoking decreased both life expectancy and years of life with activities of daily-living disability, whereas obesity decreased the former but increased the latter, thus leading to the conclusion that 'smoking kills, and obesity disables'. Reuser's conclusion is concordant with the impact of walking on life expectancy and lifetime medical expenditure. Physical activity decreases not only mortality but also disability, ${ }^{5-13} 17 \quad 1832$ leading to lower medical expenditure. ${ }^{33}$ For instance, walking has been significantly associated with a lower risk of cardiovascular disease, ${ }^{7}$ stroke, ${ }^{34}$ coronary heart disease, ${ }^{35} 36$ type 2 diabetes ${ }^{37}$ and hypertension. ${ }^{38}$ Consequently, walking also reduces expenditure on medication needed for these conditions. ${ }^{39}$

\section{Strengths and limitations}

This is the first study to have investigated the association between walking, life expectancy and lifetime medical expenditure. A major strength of this study was that we collected individual data on medical expenditure based on a cohort study of survival and medical-care utilisation, and its cost, for all participants, ${ }^{1922} 2428$ and the NHI covers almost all medical treatment in Japan. Second, we conducted a 13-year prospective observation of 27738 Japanese adults aged 40-79 years living in the community who were free of any functional limitations or chronic conditions interfering with physical activity, with an accrued total of 285342 person-years. Third, in order to reduce bias or reverse causation in that people did not walk because of functional limitations that also required medical expenditure, we excluded participants who, at the baseline, reported limited physical function or conditions interfering with physical activity. Additionally, to control for confounders, we also included various covariates in our Poisson regression model and linear regression model.

On the other hand, several limitations should also be considered. First, we assessed walking using a simple questionnaire in which we asked the participants to report only the time spent walking and did not ask about walking pace, distance walked or any distinction between walking for exercise and other reasons. Second, a longer time spent walking may be a reflection of performing more vigorous activity, making it difficult to distinguish the impact of walking from other types of physical activity. However, the present result did not change after multivariate adjustment.

\section{Conclusions and policy implication}

In summary, lifetime medical expenditure was shown to be decreased in participants who walked $\geq 1 \mathrm{~h}$ per day, despite the fact that they lived longer. Increased longevity resulting from a healthier lifestyle did not necessarily translate into an increased amount of medical expenditure throughout life. However, in the present study, around $50 \%$ of study participants walk $<1 \mathrm{~h}$ per day. To increase their walking time, the recommendation of walking with a pedometer may be useful. ${ }^{40}$ An increase in walking time at the population level would bring about a tremendous change in people's health and medical cost. A campaign to encourage people to walk for longer and a program to make walking environments safer and more pleasant should be implemented. This intervention may extend life expectancy without apparently increasing lifetime medical expenditure, especially for men. 
Author affiliations

${ }^{1}$ Division of Epidemiology, Department of Public Health and Forensic Medicine, Tohoku University Graduate School of Medicine, Sendai, Japan

${ }^{2}$ Department of Molecular Epidemiology, Genome Research Center, Tohoku University Graduate School of Medicine, Sendai, Japan

${ }^{3}$ Department of Environment and Genome Research Center, Tohoku University Graduate School of Medicine, Sendai, Japan

${ }^{4}$ Department of Public Health, Yamagata University Graduate School of Medical Science, Yamagata, Japan

${ }^{5}$ Department of Hygiene, Fujita Health University School of Medicine, Toyoake, Japan

Correction notice The "To cite: ..." information and running footer in this article have been updated with the correct volume number (volume 1).

Funding This study was supported by a Health Sciences Research Grant for Health Services (H21-Choju-Ippan-001, H20-Junkankitou (Seisyu)-Ippan-013, H22- Junkankitou (Seisyu)-Ippan-012, H23- Junkankitou (Seisyu)-Ippan-005), Ministry of Health, Labour and Welfare, Japan. MN is a recipient of a Research Fellowships of the Japan Society for the Promotion of Science for Young Scientists.

\section{Competing interests None.}

Patient consent Obtained.

Ethical approval Ethics approval was provided by the Ethics Committee of Tohoku University School of Medicine.

Contributors All authors contributed to the design of the study. MN, SK, MK, KO-M, TS and IT carried out the data collection. MN, SK, AH, MK and SH carried out the data analysis. MN, MK, KO-M, TS, AH, MK and SH wrote the report. SK and IT carried out a critical revision of the manuscript. All authors approved the final version of the report for submission.

Provenance and peer review Not commissioned; externally peer reviewed.

Data sharing statement No additional data available.

\section{REFERENCES}

1. Franco $\mathrm{OH}$, de Laet $\mathrm{C}$, Peeters $\mathrm{A}$, et al. Effects of physical activity on life expectancy with cardiovascular disease. Arch Intern Med 2005;165:2355-60.

2. Hatziandreu EI, Koplan JP, Weinstein MC, et al. A cost-effectiveness analysis of exercise as a health promotion activity. Am J Public Health 1988;78:1417-21.

3. Jonker JT, De Laet C, Franco OH, et al. Physical activity and life expectancy with and without diabetes: life table analysis of the Framingham Heart Study. Diabetes Care 2006;29:38-43.

4. Keeler EB, Manning WG, Newhouse JP, et al. The external costs of a sedentary life-style. Am J Public Health 1989;79:975-81.

5. Fujita K, Takahashi H, Miura C, et al. Walking and mortality in Japan: the Miyagi Cohort Study. J Epidemiol 2004;14(Suppl 1): S26-32.

6. Kujala UM, Kaprio J, Sarna S, et al. Relationship of leisure-time physical activity and mortality: the Finnish twin cohort. JAMA 1998;279:440-4.

7. LaCroix AZ, Leveille SG, Hecht JA, et al. Does walking decrease the risk of cardiovascular disease hospitalizations and death in older adults? J Am Geriatr Soc 1996;44:113-20.

8. Lee IM, Rexrode KM, Cook NR, et al. Physical activity and coronary heart disease in women: is 'no pain, no gain' passe? JAMA 2001;285:1447-54.

9. Morioka S. [A cohort study on the relationship between lifestyles and total mortality] (in Japanese). Nippon Koshu Eisei Zasshi 1996;43:469-78.

10. Seki N. [Relationships between walking hours, sleeping hours, meaningfulness of life (ikigai) and mortality in the elderly: prospective cohort study] (in Japanese). Nippon Eiseigaku Zasshi 2001;56:535-40.

11. Stessman J, Maaravi Y, Hammerman-Rozenberg R, et al. The effects of physical activity on mortality in the Jerusalem 70-Year-Olds Longitudinal Study. J Am Geriatr Soc 2000;48:499-504.

12. Wannamethee SG, Shaper AG, Walker M. Physical activity and mortality in older men with diagnosed coronary heart disease. Circulation 2000;102:1358-63.
13. Weller I, Corey P. The impact of excluding non-leisure energy expenditure on the relation between physical activity and mortality in women. Epidemiology 1998;9:632-5.

14. Dumurgier J, Elbaz A, Ducimetière $P$, et al. Slow walking speed and cardiovascular death in well functioning older adults: prospective cohort study. BMJ 2009;339:b4460.

15. Tanasescu M, Leitzmann MF, Rimm EB, et al. Exercise type and intensity in relation to coronary heart disease in men. JAMA 2002;288:1994-2000.

16. Cooper R, Kuh D, Hardy R. Objectively measured physical capability levels and mortality: systematic review and meta-analysis. BMJ 2010;341:c4467.

17. Hakim AA, Petrovitch $\mathrm{H}$, Burchfiel $\mathrm{CM}$, et al. Effects of walking on mortality among nonsmoking retired men. $N$ Engl $J$ Med 1998;338:94-9.

18. Lee IM, Paffenbarger RS Jr. Associations of light, moderate, and vigorous intensity physical activity with longevity. The Harvard Alumni Health Study. Am J Epidemiol 2000;151:293-9.

19. Tsuji I, Takahashi K, Nishino Y, et al. Impact of walking upon medical care expenditure in Japan: the Ohsaki Cohort Study. Int J Epidemiol 2003;32:809-14.

20. Jones TF, Eaton CB. Cost-benefit analysis of walking to prevent coronary heart disease. Arch Fam Med 1994;3:703-10.

21. Perkins AJ, Clark DO. Assessing the association of walking with health services use and costs among socioeconomically disadvantaged older adults. Prev Med 2001;32:492-501.

22. Tsuji I, Nishino Y, Ohkubo T, et al. A prospective cohort study on National Health Insurance beneficiaries in Ohsaki, Miyagi Prefecture, Japan: study design, profiles of the subjects and medical cost during the first year. J Epidemiol 1998;8:258-63.

23. Chiang CL. The Life Table and Its Applications. Malabar: Robert E Krieger Publishing Company, 1984.

24. Hayashida K, Imanaka Y, Murakami G, et al. Difference in lifetime medical expenditures between male smokers and non-smokers. Health Policy 2010;94:84-9.

25. Kuriyama S, Shimazu T, Ohmori K, et al. Green tea consumption and mortality due to cardiovascular disease, cancer, and all causes in Japan: the Ohsaki study. JAMA 2006;296:1255-65.

26. Stewart AL, Hays RD, Ware JE Jr. The MOS short-form general health survey. Reliability and validity in a patient population. Med Care 1988;26:724-35.

27. Tsubono $\mathrm{Y}$, Tsuji I, Fujita $\mathrm{K}$, et al. Validation of walking questionnaire for population-based prospective studies in Japan: comparison with pedometer. J Epidemiol 2002;12:305-9

28. Kuriyama S, Tsuji I, Ohkubo T, et al. Medical care expenditure associated with body mass index in Japan: the Ohsaki Study. Int $J$ Obes Relat Metab Disord 2002;26:1069-74.

29. Nakamura K, Okamura $\mathrm{T}$, Kanda $\mathrm{H}$, et al. Medical costs of obese Japanese: a 10-year follow-up study of National Health Insurance in Shiga, Japan. Eur J Public Health 2007;17:424-9.

30. Statistics and Information Department Minister's Secretariat, Ministry of Health, Labour and Welfare of Japan. The 20th Life Tables. Tokyo: Health and Welfare Statistics Association, Japan, 2000.

31. Reuser M, Bonneux LG, Willekens FJ. Smoking kills, obesity disables: a multistate approach of the US Health and Retirement Survey. Obesity (Silver Spring) 2009;17:783-9.

32. Clark DO. The effect of walking on lower body disability among olde blacks and whites. Am J Public Health 1996;86:57-61.

33. Mitra S, Findley PA, Sambamoorthi U. Health care expenditures of living with a disability: total expenditures, out-of-pocket expenses, and burden, 1996 to 2004. Arch Phys Med Rehabil 2009;90:1532-40.

34. Hu FB, Stampfer MJ, Colditz GA, et al. Physical activity and risk of stroke in women. JAMA 2000;283:2961-7.

35. Hakim AA, Curb JD, Petrovitch $\mathrm{H}$, et al. Effects of walking on coronary heart disease in elderly men: the Honolulu Heart Program. Circulation 1999;100:9-13.

36. Manson JE, Hu FB, Rich-Edwards JW, et al. A prospective study of walking as compared with vigorous exercise in the prevention of coronary heart disease in women. N Engl J Med 1999;341:650-8.

37. Hu FB, Sigal RJ, Rich-Edwards JW, et al. Walking compared with vigorous physical activity and risk of type 2 diabetes in women: a prospective study. JAMA 1999;282:1433-9.

38. Hayashi T, Tsumura K, Suematsu C, et al. Walking to work and the risk for hypertension in men: the Osaka Health Survey. Ann Intern Med 1999;131:21-6.

39. Williams PT. Reduced diabetic, hypertensive, and cholesterol medication use with walking. Med Sci Sports Exerc 2008;40:433-43.

40. Snyder A, Colvin B, Gammack JK, et al. Pedometer use increases daily steps and functional status in older adults. J Am Med Dir Assoc. Published Online First: 7 October 2010. doi:10.1016/j. jamda.2010.06.007. 